\title{
Tissue engineering and regeneration of lymphatic structures
}

\author{
Evan Weitman ${ }^{1}$, Daniel Cuzzone ${ }^{1}$, and Babak J Mehrara1, ${ }^{*}$ \\ ${ }^{1}$ The Department of Surgery, Plastic Surgery Section, Memorial Sloan-Kettering Cancer Center, \\ New York, NY, USA
}

\begin{abstract}
Tissue engineering is the process by which biological structures are recreated using a combination of molecular signals, cellular components and scaffolds. Although the perceived potential of this approach to reconstruct damaged or missing tissues is seemingly limitless, application of these ideas in vivo has been more difficult than expected. However, despite these obstacles, important advancements have been reported for a number of organ systems, including recent reports on the lymphatic system. These advancements are important since the lymphatic system plays a central role in immune responses, regulation of inflammation, lipid absorption and interstitial fluid homeostasis. Insights obtained over the past two decades have advanced our understanding of the molecular and cellular mechanisms that govern lymphatic development and function. Utilizing this knowledge has led to important advancements in lymphatic tissue engineering, which is the topic of this review.
\end{abstract}

\section{Keywords}

lymph node; lymphatic; lymphatic endothelial cell; lymphedema; tissue engineering

\begin{abstract}
Although the theoretical implications of tissue engineering have been known for some time, the practical and clinical implications are only beginning to be realized. Recent reports have detailed important advancements in tissue engineering of relatively simple anatomic structures, such as skin, blood vessels and bone [1-5]. In addition, remarkable advancements have been reported in the engineering of complex organ systems, such as the trachea, urinary bladder, liver and pancreas [6-16].
\end{abstract}

More recently, there has been a growing interest in applying tissue engineering principles for reconstruction of the lymphatic system. This interest is based on the fact that the lymphatics play an instrumental role in regulation of immunologic, circulatory and metabolic systems [17]. In addition, the lymphatics are commonly injured or rendered

\footnotetext{
(C) 2013 Future Medicine Ltd

*Author for correspondence: mehrarab@mskcc.org.

Financial \& competing interests disclosure

The authors have no relevant affiliations or financial involvement with any organization or entity with a financial interest in or financial conflict with the subject matter or materials discussed in the manuscript. This includes employment, consultancies, honoraria, stock ownership or options, expert testimony, grants or patents received or pending, or royalties.

No writing assistance was utilized in the production of this manuscript.

For reprint orders, please contact: reprints@futuremedicine.com
} 
dysfunctional either due to trauma, iatrogenically during the course of cancer treatment, as a consequence of genetic abnormalities, or secondary to infections. These disturbances result in significant morbidity and are difficult to treat with conventional approaches. For example, removal of lymph nodes during the course of cancer treatment (lymphadenectomy) is associated with the development of lymphedema in 30-50\% of patients, resulting in chronic swelling, recurrent life threatening infections and deadly secondary malignancies [18-20]. Lymphedema is an even bigger source of morbidity worldwide, afflicting as many as 200 million people as a consequence of parasitic infections (filariasis) [21]. There is currently no treatment for these patients, many of whom go on to develop devastating complications with little hope. There is, therefore, a tremendous unmet need in treating disorders of the lymphatics and the complications that result from these diseases.

Engineering of the lymphatic system can be broadly categorized into growth factor approaches that promote regeneration of lymphatic vessels, cellular strategies designed to deliver lymphatic endothelial cells (LECs) or stem cells, and complex approaches using a combination of growth factors, cells and scaffolds. This review will summarize advances in these fields and outline potential future directions that may ultimately lead to successful lymphatic tissue engineering.

\section{Anatomy \& physiology of the lymphatic system}

The lymphatic vascular network can be broadly divided into the initial lymphatic vessels (lymphatic capillaries) where interstitial fluid enters the system forming lymph, the collecting lymphatics that transport the lymph back to the central venous vasculature, and lymph nodes located at discrete regions through which lymph fluid drains.

The lymphatic network is lined by specialized endothelial cells known as LECs. LECs are structurally similar to blood endothelial cells (BECs) and are derived embryologically from outbranching of BECs from the cardinal vein [22]. Differentiation of LECs is dependent on the expression of lymphatic specific genes, including the transcription factor PROX-1. $P R O X-1$ is thought to play a central role in LEC differentiation and is referred to as the master lymphatic regulator, since BECs that bud off the cardinal veins of $P R O X-1$ knockout mice fail to express lymphatic markers or form lymphatic structures [23]. Continuous PROX-1 expression, even after lymphatic differentiation, is necessary for maintenance of lymphatic phenotype by upregulating the expression of lymphatic markers and downregulating the expression of BEC genes [24]. Other lymphatic specific genes include $L Y V E-1$, podoplanin and VEGF-R3 [25,26]. Identification of these markers has greatly facilitated the study of LECs since it has enabled rapid and simple techniques for establishing LEC cultures [27].

\section{Capillary lymphatics}

Capillary lymphatics are small, blind-ended vessels located in the superficial dermis. Compared with blood capillaries, lymphatic capillaries are much more variable in size (10$60 \mu \mathrm{m}$ ) and often appear collapsed [28]. Lymphatic capillaries have thin walls made up of a single layer of LECs, covered by very little patchy basement membrane and no support (mural) cells [29]. The vessels have the unique ability to form transient gaps in the 
endothelial wall in order to allow interstitial fluid to enter the vessel to form lymph. This ability is due to the partial overlapping projections from the LECs, which also gives them their distinctive ultrastructural oak leaf shape. The projections are linked to the extracellular matrix via fine anchoring filaments and help to maintain structural integrity and act as a 'micro' or primary valve in the capillary lymphatic wall [30-33]. In this way, increased interstitial fluid pressure is thought to open lymphatic vessels by displacing the anchoring filaments, thus enabling the entrance of interstitial fluid into the initial lymphatics.

Capillary LECs are similar to BECs; however, they lack a continuous basement membrane and surrounding pericytes. Capillary LECs are bound to collagen filaments in the matrix via emilin-1 and fibrillin; these filaments accommodate changes in interstitial fluid pressure, enhancing LEC permeability and subsequent transit of fluid into the lymphatic circulation. There are a number of integrins that are expressed by LECs and these interact with anchoring filaments to maintain structural integrity during movement of fluid from the interstitium into lymphatic vessels [34].

\section{Collecting lymphatics \& lymphangions}

The lymphatic capillaries merge and drain lymph into precollecting lymphatic vessels, which vary in length and composition from organ to organ [35]. Precollecting lymphatic vessels are different from the capillary lymphatics in that they contain intraluminal (secondary) valves preventing back flow of lymph [36], the LECs are more spindle shaped and adhere to each other in a more continuous manner ('zipper' junction), and have a more continuous basement membrane with an associated smooth muscle cell cover enabling intrinsic contractility of the vessels.

Precollectors subsequently merge into larger lymphatics known as collecting lymphatic vessels, which are made up of chains of subunits called lymphangions (defined as the section between two secondary valves) (Figure 1). Similar to blood vessels, the wall structure of collecting lymphatics is organized into a layer of continuously adherent LECs (intima), and layers of basement membrane and circumferential smooth muscle (media) [35]. Lymphangions act individually or in groups to form contractile units that can propel lymph in a controlled way (similar to gut peristalsis) downstream to the next lymphangion(s). Laminin and type IV collagen comprise the main components of lymphatic and blood vessel basement membranes [37].

Lymphatic valves are located intraluminally and are made up of connective tissue covered with LECs. They have a bileaflet pattern tapering intraluminally to meet the opposite valve and inserting into the lymphatic wall. Lymphatic fluid flow from downstream contractions causes the more upstream part of the valve leaflets to bulge inwards, occluding the space and preventing back flow. Conversely, fluid pressure upstream opens the valve [38].

Collecting lymphatics are between 50-200 $\mu \mathrm{m}$ in diameter. Regarding blood vessels, average diameters are as follows: vein $(5 \mathrm{~mm})$, venule $(20 \mu \mathrm{m})$, capillary $(9 \mu \mathrm{m})$, arteriole $(37 \mu \mathrm{m})$, muscular artery $(6 \mathrm{~mm})$ and elastic artery $(1.5 \mathrm{~cm})$ [39]. Pericytes are vascular mural cells that surround BECs as well as larger collecting lymphatics. They are important in regulating vascular development, stabilization and maturation of blood vessels. 
Endothelial cells and pericytes are interdependent, and genetic models demonstrate that elimination of either causes dysfunction in the other. There are normally no surrounding mural cells around the smaller initial and microlymphatics. Interestingly, however, mural cells can be recruited to smaller lymphatic vessels in pathologic conditions. In the case of lymphedema-distichiasis syndrome, a mutation in the FoxC2 gene leads to ectopic recruitment of mural cells to capillary lymphatic vessels with subsequent narrowing and lymph stasis [40,41]. LEC and BEC characteristics have been compared in Table 1.

\section{Lymph nodes}

Lymph nodes are located at various regions in the body and filter lymphatic fluid enabling peripheral antigen presenting cells to meet and educate naive T cells [42]. The lymph node is encased in a fibrous capsule that lines an underlying subcapsular sinus. Afferent lymphatic vessels penetrate the capsule, drain into the subcapsular sinus and enter the cortex. The cortex has two main components: a paracortex, predominantly populated by $\mathrm{T}$ cells, and a germinal center, comprised largely of B cells. Circulating lymphocytes initially enter the paracortex, which functions as a site of antigen presentation to $\mathrm{T}$ cells via dendritic cells. Germinal centers function mainly as a site for humoral responses. Lymphatic fluid drains through the peripheral cortex via trabecular sinuses and into the deeper medullary region via medullary sinuses. These sinuses are separated by medullary cords, which are permeated by reticular fibers. Lymphatic fluid ultimately drains towards the hilum through a fibroblastic reticular cell conduit and exits the lymph node via an efferent lymphatic vessel to facilitate the transport and clearance of extravascular fluid from the tissues. The systemic circulation interacts with the lymph node via high endothelial venules in the cortex [43].

\section{Tissue engineering \& regeneration of lymphatics}

\section{Growth factor-based approaches to tissue engineering}

The identification of lymphatic-specific cellular markers was a significant advance in the study of the lymphatic system since these markers enabled researchers to distinguish lymphatics from blood vessels in vivo. Using these techniques in embryo-logic and wound healing studies led to the discovery of critical molecules, such as VEGF-C, VEGF-D and their receptor VEGF-R3, which regulate lymphatic development and regeneration [44,45].

Not surprisingly, the identification of potent lymphangiogenic molecules, such as VEGF-C, led to the exogenous application of these molecules in models of lymphatic injury or aplasia in an effort to improve lymphatic function. Indeed, these approaches have been shown to be highly successful in a number of experiments. For example, intradermal ear injection of recombinant VEGF-C-expressing adeno-associated virus has been shown to be an effective means of promoting lymphatic sprouting and growth in a congenital model of primary lymphedema that lacks capillary lymphatics [46]. Similarly, delivery of VEGF-C either as a recombinant protein, viral vector or naked plasmid has been shown to ameliorate surgically induced lymphedema in rabbit [47], mouse [48], rat [49] and sheep [50] models, promote lymphatic regeneration across skin flap incisions [51], and improve lymphatic regeneration and function after lymph node transfer in mice, rats, pigs and sheep [52-55]. 
In addition to VEGF-C, a number of other growth factors have been shown to have potent lymphangiogenic activity, including FGF [56,57], HGF [58,59], IGF [60] and PDGF $[61,62]$. However, the effects of these growth factors on ameliorating lymphedema (either primary or surgical) has only been studied in a few reports [59]. Veikkola et al. created a transgenic mouse overexpressing a VEGFR3-specific mutant of VEGF-C (VEGF-C156S). Importantly, using this mouse model they were able to stimulate lymphangiogenesis without angiogenesis [63].

While a tremendous amount of research has been directed towards identification and use of lymphangiogenic molecules to promote lymphatic regeneration, more recent studies have focused on antilymphangiogenic mechanisms. These studies were based, in part, on the observation that in some pathologic circumstances lymphatic function is impaired despite increased or normal expression of lymphangiogenic cytokines, such as VEGF-C. This apparent paradox suggests that other physiological mechanisms are either directly or indirectly inhibiting lymphatic regeneration in these circumstances. For example, using a mouse tail model of lymphedema, Rutkowski and colleagues [64] and later Goldman et al. [65] from the same laboratory demonstrated that either endogenous VEGF-C expression or even overexpression of VEGF-C using cell-based gene therapy approaches is insufficient to promote lymphatic regeneration in the setting of lymphedema. Using the same model, Avraham et al. found that lymphatic function and lymphatic regeneration could be significantly improved either by local or systemic inhibition of TGF- $\beta 1$ [66]. TGF- $\beta 1$ has been shown to have potent antilymphangiogenic activity resulting in decreased LEC proliferation, downregulation of lymphatic specific gene expression, impaired lymphatic tubule formation and markedly decreased in vivo LEC migration [67]. This concept is supported by the findings of Yan et al. who used an in vivo matrigel lymphangiogenesis assay to show that TGF- $\beta 1$ inhibition synergistically increases the lymphangiogenic effects of VEGF-C [68]. In this study, matrigel was used as a matrix to provide cells with a stable infrastructure for cellular ingrowth and development. Thus, tissue engineering approaches can be designed to augment lymphangiogenesis by altering the balance between lymphangiogenic and antilymphangiogenic forces. This concept is clinically relevant since the use of lymphangiogenic growth factors, such as VEGF-C, is in some cases contraindicated. For example, although VEGF-C-based approaches may be theoretically helpful in promoting lymphatic regeneration in patients with lymphatic injury secondary to cancer treatment, this approach may also inadvertently lead to tumor growth or metastasis since VEGF-C expression has been shown to contribute to these processes [69,70]. In addition, recent reports have suggested that VEGF-C therapy can exacerbate edema and inflammation by promoting formation of poorly functioning, leaky and hyperplastic lymphatic vessels $[64,65]$. In these cases, therefore, inhibition of antilymphangiogenic mechanisms may be a better alternative.

More recent reports have identified other potent antilymphangiogenic molecules, including cytokines, such as IFN- $\gamma$, and extracellular matrix proteins, such as endostatin. IFN- $\gamma$ is particularly interesting and appears to serve as an important link between inflammation and lymphangiogenesis. For example, Kataru et al. demonstrated that T-cell production of IFN- $\gamma$ potently inhibits lymph node lymphangiogenesis and that this mechanism is a physiological 
means by which inflammatory lymphangiogenesis in the lymph node is resolved [71]. They

found that, similar to TGF- $\beta 1$, IFN- $\gamma$ is a potent inhibitor of LEC proliferation and differentiation, and that these effects are independent of VEGF-C or -A. Similarly, using a mouse-tail model of lymphedema, Zampell et al. found that lymphatic regeneration is impaired by increased expression of IFN- $\gamma$ and TGF- $\beta 1$, and that this process was related to T-cell inflammation [72]. These studies, therefore, suggest that a number of strategies are available for manipulating the lymphangiogenesis-antilymphangiogenesis axis and that these approaches may increase the potential for lymphatic regeneration and function.

\section{Cellular approaches to tissue engineering \& regeneration}

Isolation and analysis of LECs in vitro has increased our understanding of the lymphatic system and has served as a key step in lymphatic tissue engineering. These studies have been greatly facilitated by isolation of pure LEC populations using lymphatic specific markers, such as LYVE-1 and podoplanin [73-78]. A number of published techniques have been described and rely primarily on cell sorting or the use of magnetic beads for cell enrichment. Importantly, isolation of pure LEC and BEC populations has enabled comparative studies that identify key differences in gene expression and cellular make up between these closely related cell types [79]. These differences have been shown to play a crucial role in the regulation of lymphatic organization and function, and this remains an active area of research.

Swartz has been a pioneer in lymphatic tissue engineering and has published extensively in this arena. In an interesting study from her laboratory, Dixon et al. showed that by allowing enterocytes to seed a transwell dish and then adding LECs to the mixture that they were able to create a model of an intestinal lacteal to study lymphatic-enterocyte interphase and lipid transport [80]. Although these tissue engineered constructs were rudimentary in structure, this study is an interesting proof of concept that complex interactions between LECs and stromal cells can be modeled in vitro and have the potential for recapitulation of complex interactions.

Swartz and colleagues have also made important contributions to our understanding of the role of interstitial fluid flow in the regulation of LEC proliferation, migration and function. In an interesting study comparing the effect of interstitial flow (10 $\mu \mathrm{m} / \mathrm{s}$ for 6 days) on BECs and LECs in 3D collagen gel cultures, $\mathrm{Ng}$ et al. found that these cell types had differential responses to interstitial flow resulting in differences in cellular morphology and branching patterns, suggesting that LEC differentiation imparts specialized responses to environmental stimuli [81]. The importance of this concept was further demonstrated using an in vivo mouse model of lymphatic regeneration, demonstrating that interstitial fluid flow acts as a guide for LEC migration and VEGF-C expression, and that lymphatic regeneration occurs in the direction of lymphatic fluid flow [82]. In a follow-up study, using a mouse tail model of lymphatic regeneration in which the flow of interstitial fluid could be shunted, Goldman and colleagues demonstrated that interstitial fluid flow is not only sufficient but also necessary for lymphatic vessel regeneration [83]. Taken together, these studies suggest that tissue engineered lymphatic constructs should be designed using scaffolds that promote interstitial fluid flow. 
Similar to BECs, LECs form 3D tubular structures when placed on matrigel or other scaffolds. This response is greatly increased with exposure of cells to lymphangiogenic cytokines or inhibition of antilymphangiogenic growth factors. In fact, the matrigel tubule formation and matrigel lymphangiogenesis assays are standard techniques by which LEC function is assayed [66]. Dai et al. took advantage of this phenomenon by analyzing the effect of culturing LECs in a polyglycolic acid (PGA) scaffold in vitro and then transferring these constructs in vivo in an attempt to tissue engineer a lymphatic vascular network [84]. The theoretical advantage of PGA scaffolds in this case is that these constructs can be custom designed and shaped, and the rigidity of the scaffold can be easily manipulated. Thus, in contrast to matrigel, which has the consistency of jelly, PGA scaffolds can be designed to have structural integrity enabling surgical handling and transfer, and are biodegradable and biocompatible. Interestingly, Dai and colleagues found that LECs proliferated in these constructs with little evidence of toxicity and that subcutaneous transfer into nude mice did not result in resorption of the lymphatic network (at least in the short term). This work is preliminary, however, since formation of primitive lymphatic networks does not recreate the complex lymphatic network and does not have lymphatic supportive structures (e.g., valves and smooth muscle coverage) necessary for unidirectional (i.e., lymphangion) lymphatic transport and function.

A number of studies have shown that under the appropriate circumstances lymphatic vessels can migrate into and repopulate lymphatic tissues [85-87]. Similarly, lymphatic vessels have been shown to spontaneously reconnect with existing lymphatic networks after tissue transfer [88]. These findings are important since they suggest that lymphatic networks can be created using biological scaffolds that promote LEC ingrowth and that these networks may become functional if the appropriate stimuli are provided. Based on this concept, Wong et al. evaluated the potential for acellular dermal matrices as a biological scaffold for lymphatic vessel ingrowth, and found that both blood and lymphatic vessel ingrowth occurs rapidly in decellularized dermis recreating the typical dermal capillary and lymphatic appearance of skin [89]. The dermal matrix is rapidly incorporated into the surrounding structures and, due to the decellularization process, engenders little inflammatory response. These findings are exciting since they suggest that decellularized constructs can be used to provide the necessary scaffold and extracellular signaling molecules required for guided lymphatic tissue regeneration.

Although a relatively large number of studies have analyzed the transfer and use of isolated LECs for lymphatic regeneration, only a few have reported on the use of multipotent progenitor cells. However, recent studies have shown that embryonic stem cells can differentiate into LECs in vitro under appropriate conditions [90-92]. Other studies have shown that mesenchymal stem cells (MSCs) derived either from bone marrow or fat can express LEC markers (prox-1, VEGF-C, VEGF-A) and that stimulation of these cells in cultured media with recombinant VEGF-C, even for brief periods of time in vitro, markedly increased their ability to promote lymphangiogenesis in vivo [68]. Other studies have shown a therapeutic effect of adipose-derived MSCs in rat hindlimb and mouse tail models of lymphedema demonstrating that delivery of stem cells either by direct injection or in hydrogel markedly decreases tissue edema, improves lymphatic regeneration and restores 
lymphatic fluid flow $[93,94]$. Furthermore, these studies suggested that at least some of the delivered MSCs exhibit an LEC phenotype in vivo. These studies are important because adipose-derived MSCs are easily harvested and available in large quantities and may represent a better option than isolation and expansion of LECs for lymphatic tissue engineering.

\section{Artificial/tissue-engineered lymphatic organs}

A few studies have attempted to tissue engineer lymph nodes either in vitro or in vivo. Giese and colleagues used a bioreactor system with agarose and nonwoven polyamide fiber scaffolds, dendritic cells and peripheral blood mononuclear cells to tissue engineer lymphoid-like structures containing antigen-specific, cytokine responsive lymphocytes in 11 days [95]. However, although these findings were exciting, the authors have not reported in vivo implantation or use. By contrast, Watanabe et al. used a different approach to tissue engineer functional lymphoid organs in vivo by seeding collagen gel scaffolds with dendritic cells and thymic stromal cells that constitutively expressed lymphotoxin-a (LT-a) $[96,97]$. LT-a is largely responsible for lymphoid tissue organogenesis. This has been demonstrated by showing that $L T$-a knockout mice are phenotypically normal and have functional CD4 and CD8 T cells, as well as intact lymphatic vessels, but lack any lymph node or Peyer's patch development [98]. Implantation of LT-a-expressing scaffolds in the renal capsule resulted in cellular reorganization, chemoattraction of circulating lymphocytes with clustering and ingrowth of high endothelial venules. More importantly, the authors showed that these organs were immunologically functional and capable of producing antigenspecific antibodies in immunocompromised animals. Restoration of immunologic and circulatory function has been elusive but is an important goal since this step may provide alternative treatments for patients with lymphedema or those who have experienced lymphatic injury.

\section{Conclusion \& future perspective}

It is clear that lymphatic defects and the morbidity associated with these problems are an important unmet clinical need. Advancements in our understanding of lymphatic biology have led to the identification of growth factors that regulate lymphatic regeneration and improved function. Similarly, isolation and culture of LECs has enabled us to experiment with culture systems and scaffolds to produce artificial lymphatic structures.

The future of lymphatic vessel engineering depends on applying all of the principles mentioned in this manuscript, namely the creation of lymphatic vessels, facilitating connection of those lymphatic vessels to systemic structures, designing functional lymphatic structures, such as lymph nodes, and providing vascularization of the lymphatic system. Successful lymphatic tissue engineering will require a sound infrastructure to support lymphatic circulation via scaffolds and artificial lymphatic organs as well as the functionality to accomplish all of the roles typically managed by the lymphatic system, such as fat transport, immune cell trafficking and interstitial fluid regulation. The challenge going forward will be the development of techniques to combine these structures to create functional lymphatic organs and to deliver these constructs clinically. This next step will require development of vascular networks that can connect to existing host networks and 
enable incorporation into the new host. There has been considerable progress in vascular tissue engineering and those principles will require integration into lymphatic tissue engineering for fully functional and well-vascularized artificial structures [99]. The ultimate goal of developing and implanting a functional lymphatic construct is still constrained by formidable challenges; however, the potential to make such constructs is becoming increasingly feasible with recent developments in tissue engineering, and clinical application for the treatment of lymphatic disease is within reach.

\section{References}

Papers of special note have been highlighted as:

- of interest

1. Eberli D, Rodriguez S, Atala A, Yoo JJ. In vivo evaluation of acellular human dermis for abdominal wall repair. J Biomed Mater Res Part A. 2010; 93(4):1527-1538.

2. Lumpkins SB, Pierre N, Mcfetridge PS. A mechanical evaluation of three decellularization methods in the design of a xenogeneic scaffold for tissue engineering the temporomandibular joint disc. Acta Biomater. 2008; 4(4):808-816. [PubMed: 18314000]

3. Mclafferty E, Hendry C, Alistair F. The integumentary system: anatomy, physiology and function of skin. Nurs Stand. 2012; 27(3):35-42.

4. Stegemann JP, Kaszuba SN, Rowe SL. Review: advances in vascular tissue engineering using protein-based biomaterials. J Tissue Eng. 2007; 13(11):2601-2613.

5. Hoenig MR, Campbell GR, Rolfe BE, Campbell JH. Tissue engineered blood vessels: alternative to autologous grafts? Arterioscler Thromb Vasc Biol. 2005; 25(6):1128-1134. [PubMed: 15705929]

6. Baiguera S, Birchall MA, Macchiarini P. Tissue engineered tracheal transplantation. Transplantation. 2010; 89(5):485-491. [PubMed: 20061996]

7. Baiguera S, Jungebluth $\mathrm{P}$, Burns A, et al. Tissue engineered human tracheas for in vivo implantation. Biomaterials. 2010; 31(34):8931-8938. Demonstrated the feasibility and applicability of bioengineering a trachea with the structural and mechanical properties necessary for in vivo implantation. [PubMed: 20800273]

8. Conconi MT, De Coppi P, Di Liddo R, et al. Tracheal matrices, obtained by a detergent-enzymatic method, support in vitro the adhesion of chondrocytes and tracheal epithelial cells. Transpl Int. 2005; 18(6):727-734. [PubMed: 15910302]

9. Macchiarini P, Jungebluth $\mathrm{P}$, Go T, et al. Clinical transplantation of a tissue engineered airway. Lancet. 2008; 372(9655):2023-2030. [PubMed: 19022496]

10. Murphy SV, Atala A. Organ engineering - combining stem cells, biomaterials, and bioreactors to produce bioengineered organs for transplantation. Bioessays. 2013; 35(3):163-172. [PubMed: 22996568]

11. Yoo JJ, Meng J, Oberpenning F, Atala A. Bladder augmentation using allogenic bladder submucosa seeded with cells. Urology. 1998; 51(2):221-225. [PubMed: 9495701]

12. Sellaro TL, Ravindra AK, Stolz DB, Badylak SF. Maintenance of hepatic sinusoidal endothelial cell phenotype in vitro using organ-specific extracellular matrix scaffolds. J Tissue Eng. 2007; 13(9):2301-2310.

13. Ito A, Takizawa $\mathrm{Y}$, Honda $\mathrm{H}$, et al. Tissue engineering using magnetite nanoparticles and magnetic force: heterotypic layers of cocultured hepatocytes and endothelial cells. J Tissue Eng. 2004; 10(5-6):833-840.

14. Detzel CJ, Kim Y, Rajagopalan P. Engineered three-dimensional liver mimics recapitulate critical rat-specific bile acid pathways. J Tissue Eng Part A. 2011; 17(5-6):677-689.

15. Song YC, Chen ZZ, Mukherjee N, et al. Vitrification of tissue engineered pancreatic substitute. Transplant Proc. 2005; 37(1):253-255. [PubMed: 15808611] 
16. Kaufman-Francis K, Koffler J, Weinberg N, Dor Y, Levenberg S. Engineered vascular beds provide key signals to pancreatic hormone-producing cells. PLoS One. 2012; 7(7):e40741. [PubMed: 22808248]

17. Chakraborty S, Zawieja S, Wang W, Zawieja DC, Muthuchamy M. Lymphatic system: a vital link between metabolic syndrome and inflammation. Ann NY Acad Sci. 2010; 1207(Suppl 1):E94E102. [PubMed: 20961312]

18. Beesley V, Janda M, Eakin E, Obermair A, Battistutta D. Lymphedema after gynecological cancer treatment: prevalence, correlates, and supportive care needs. Cancer. 2007; 109(12):2607-2614. [PubMed: 17474128]

19. Hayes SC, Janda M, Cornish B, Battistutta D, Newman B. Lymphedema after breast cancer: incidence, risk factors, and effect on upper body function. J Clin Oncol. 2008; 26(21):3536-3542. [PubMed: 18640935]

20. Petrek JA, Senie RT, Peters M, Rosen PP. Lymphedema in a cohort of breast carcinoma survivors 20 years after diagnosis. Cancer. 2001; 92(6):1368-1377. [PubMed: 11745212]

21. Rockson SG, Rivera KK. Estimating the population burden of lymphedema. Ann NY Acad Sci. 2008; 1131:147-154. [PubMed: 18519968]

22. Srinivasan RS, Dillard ME, Lagutin OV, et al. Lineage tracing demonstrates the venous origin of the mammalian lymphatic vasculature. Genes Dev. 2007; 21(19):2422-2432. [PubMed: 17908929]

23. Harvey NL, Srinivasan RS, Dillard ME, et al. Lymphatic vascular defects promoted by PROX1 haploinsufficiency cause adult-onset obesity. Nat Genet. 2005; (10):1072-1081. [PubMed: 16170315]

24. Johnson NC, Dillard ME, Baluk P, et al. Lymphatic endothelial cell identity is reversible and its maintenance requires PROX1 activity. Genes Dev. 2008; 22(23):3282-3291. [PubMed: 19056883]

25. Oliver G, Alitalo K. The lymphatic vasculature: recent progress and paradigms. Annu Rev Cell Dev Biol. 2005; 21:457-483. [PubMed: 16212503]

26. Birke K, Lutjen-Drecoll E, Kerjaschki D, Birke MT. Expression of podoplanin and other lymphatic markers in the human anterior eye segment. Invest Opthalmol Vis Sci. 2010; 51(1):344-354.

27. Kazenwadel J, Secker GA, Betterman KL, Harvey NL. In vitro assays using primary embryonic mouse lymphatic endothelial cells uncover key roles for FGFR1 signalling in lymphangiogenesis. PLoS One. 2012; 7(7):e40497. [PubMed: 22792354]

28. Swartz MA, Skobe M. Lymphatic function, lymphangiogenesis, and cancer metastasis. Microsc Res Tech. 2001; 55(2):92-99. [PubMed: 11596154]

29. Parsons RJ, Mcmaster PD. The effect of the pulse upon the formation and flow of lymph. J Exp Med. 1938; 68(3):353-376. [PubMed: 19870793]

30. Casley-Smith JR, Florey HW. The structure of normal small lymphatics. Q J Exp Physio Cogn Med Sci. 1961; 46:101-106.

31. Leak LV, Burke JF. Ultrastructural studies on the lymphatic anchoring filaments. J Cell Biol. 1968; 36(1):1292149.

32. Schmid-Schonbein GW. Mechanisms causing initial lymphatics to expand and compress to promote lymph flow. Arch Histol Cytol. 1990; 53(Suppl):107-114. [PubMed: 2252623]

33. Trzewik J, Mallipattu SK, Artmann GM, Delano FA, Schmid-Schonbein GW. Evidence for a second valve system in lymphatics: endothelial microvalves. FASEB J. 2001; 15(10):1711-1717. [PubMed: 11481218]

34. Chen J, Alexander JS, Orr AW. Integrins and their extracellular matrix ligands in lymphangiogenesis and lymph node metastasis. J Cell Biol. 2012; 2012:853703.

35. Baluk P, Fuxe J, Hashizume H, et al. Functionally specialized junctions between endothelial cells of lymphatic vessels. J Exp Med. 2007; 204(10):2349-2362. [PubMed: 17846148]

36. Schmid-Schonbein GW. The second valve system in lymphatics. Lymphat Res Biol. 2003; 1(1): 25-29. discussion 29-31. [PubMed: 15624318]

37. Maatta M, Liakka A, Salo S, Tasanen K, Bruckner-Tuderman L, Autio-Harmainen H. Differential expression of basement membrane components in lymphatic tissues. J Histochem Cytochem. 2004; 52(8):1073-1081. [PubMed: 15258183] 
38. Zawieja DC. Contractile physiology of lymphatics. Lymphat Res Biol. 2009; 7(2):87-96. [PubMed: 19534632]

39. Scallan, J.; Huxley, VH.; Korthuis, RJ. Capillary fluid exchange: regulation, functions, and pathology. In: Granger, ND.; Granger, JP., editors. Colloquium Series on Integrated Systems Physiology. Morgan and Claypool Life Sciences; CA, USA: 2010.

40. Armulik A, Abramsson A, Betsholtz C. Endothelial/pericyte interactions. Circ Res. 2005; 97(6): 512-523. [PubMed: 16166562]

41. Petrova TV, Karpanen T, Norrmen C, et al. Defective valves and abnormal mural cell recruitment underlie lymphatic vascular failure in lymphedema distichiasis. Nat Med. 2004; 10(9):974-981. [PubMed: 15322537]

42. Randolph GJ, Angeli V, Swartz MA. Dendritic-cell trafficking to lymph nodes through lymphatic vessels. Nat Rev Immunol. 2005; 5(8):617-628. [PubMed: 16056255]

43. Von Andrian UH, Mempel TR. Homing and cellular traffic in lymph nodes. Nat Rev Immunol. 2003; 3(11):867-878. [PubMed: 14668803]

44. Oh SJ, Jeltsch MM, Birkenhager R, et al. VEGF and VEGF-C: specific induction of angiogenesis and lymphangiogenesis in the differentiated avian chorioallantoic membrane. Dev Biol. 1997; 188(1):96-109. [PubMed: 9245515]

45-. Joukov V, Pajusola K, Kaipainen A, et al. A novel vascular endothelial growth factor, VEGF-C, is a ligand for the Flt4 (VEGFR3) and KDR (VEGFR-2) receptor tyrosine kinases. EMBO J. 1996; 15(7):1751. Describes the potential therapeutic capacity of VEGF-C to induce lymphangiogenesis in a model of acquired lymphedema. [PubMed: 8612600]

46. Karkkainen MJ, Saaristo A, Jussila L, et al. A model for gene therapy of human hereditary lymphedema. Proc Natl Acad Sci USA. 2001; 98(22):12677-12682. [PubMed: 11592985]

47. Szuba A, Skobe M, Karkkainen MJ, et al. Therapeutic lymphangiogenesis with human recombinant. VEGF-C FASEB J. 2002; 16(14):1985-1987.

48. Yoon YS, Murayama T, Gravereaux E, et al. VEGF-C gene therapy augments postnatal lymphangiogenesis and ameliorates secondary lymphedema. J Clin Invest. 2003; 111(5):717-725. [PubMed: 12618526]

49. Liu Y, Fang Y, Dong P, et al. Effect of vascular endothelial growth factor $\mathrm{C}(V E G F-C)$ gene transfer in rat model of secondary lymphedema. Vascul Pharmacol. 2008; 49(1):44-50. [PubMed: 18571474]

50. Baker A, Kim H, Semple JL, et al. Experimental assessment of pro-lymphangiogenic growth factors in the treatment of post-surgical lymphedema following lymphadenectomy. Breast Cancer Res. 2010; 12(5):R70. [PubMed: 20825671]

51. Saaristo A, Tammela T, Timonen J, et al. Vascular endothelial growth factor-C gene therapy restores lymphatic flow across incision wounds. FASEB J. 2004; 18(14):1707-1709. [PubMed: 15361472]

52-. Tammela T, Saaristo A, Holopainen T, et al. Therapeutic differentiation and maturation of lymphatic vessels after lymph node dissection and transplantation. Nat Med. 2007; 13(12):14581466. Demonstrated that using VEGF in conjunction with a lymph node transfer resulted in improved functional and structural integration. [PubMed: 18059280]

53. Honkonen KM, Visuri MT, Tervala TV, et al. Lymph node transfer and perinodal lymphatic growth factor treatment for lymphedema. Ann Surg. 2012; 257(5):961-967. [PubMed: 23013803]

54. Sommer T, Buettner M, Bruns F, Breves G, Hadamitzky C, Pabst R. Improved regeneration of autologous transplanted lymph node fragments by VEGF-C treatment. Anat Rec (Hoboken). 2012; 295(5):786-791. [PubMed: 22419614]

55. Lahteenvuo M, Honkonen K, Tervala T, et al. Growth factor therapy and autologous lymph node transfer in lymphedema. Circulation. 2011; 123(6):613-620. [PubMed: 21282502]

56. Chang LK, Garcia-Cardena G, Farnebo F, et al. Dose-dependent response of FGF-2 for lymphangiogenesis. Proc Natl Acad Sci USA. 2004; 101(32):11658-11663. [PubMed: 15289610]

57. Cao R, Eriksson A, Kubo H, Alitalo K, Cao Y, Thyberg J. Comparative evaluation of FGF-2-, VEGF-A-, and VEGF-C-induced angiogenesis, lymphangiogenesis, vascular fenestrations, and permeability. Circ Res. 2004; 94(5):664-670. [PubMed: 14739162] 
58. Kajiya K, Hirakawa S, Ma B, Drinnenberg I, Detmar M. Hepatocyte growth factor promotes lymphatic vessel formation and function. EMBO J. 2005; 24(16):2885-2895. [PubMed: 16052207]

59. Saito Y, Nakagami H, Morishita R, et al. Transfection of human hepatocyte growth factor gene ameliorates secondary lymphedema via promotion of lymphangiogenesis. Circulation. 2006; 114(11):1177-1184. [PubMed: 16952986]

60. Bjorndahl M, Cao R, Nissen LJ, et al. Insulin-like growth factors 1 and 2 induce lymphangiogenesis in vivo. Proc Natl Acad Sci USA. 2005; 102(43):15593-15598. [PubMed: 16230630]

61. Cao Y. Direct role of PDGF-BB in lymphangiogenesis and lymphatic metastasis. Cell Cycle. 2005; 4(2):228-230. [PubMed: 15655347]

62. Onimaru M, Yonemitsu Y, Fujii T, et al. VEGF-C regulates lymphangiogenesis and capillary stability by regulation of PDGF-B. Am J Physiol Heart Circ Physiol. 2009; 297(5):H1685-1696. [PubMed: 19734356]

63. Veikkola T, Jussila L, Makinen T, et al. Signalling via vascular endothelial growth factor receptor-3 is sufficient for lymphangiogenesis in transgenic mice. EMBO J. 2001; 20(6):12231231. [PubMed: 11250889]

64. Rutkowski JM, Moya M, Johannes J, Goldman J, Swartz MA. Secondary lymphedema in the mouse tail: Lymphatic hyperplasia, VEGF-C upregulation, and the protective role of MMP-9. Microvasc Res. 2006; 72(3):161-171. [PubMed: 16876204]

65. Goldman J, Le TX, Skobe M, Swartz MA. Overexpression of VEGF-C causes transient lymphatic hyperplasia but not increased lymphangiogenesis in regenerating skin. Circ Res. 2005; 96(11): 1193-1199. [PubMed: 15890974]

66. Avraham T, Daluvoy S, Zampell J, et al. Blockade of transforming growth factor-beta1 accelerates lymphatic regeneration during wound repair. Am J Pathol. 2010; 177(6):3202-3214. [PubMed: 21056998]

67. Clavin NW, Avraham T, Fernandez J, et al. TGF-beta1 is a negative regulator of lymphatic regeneration during wound repair. Am J Pathol Heart Circ Physiol. 2008; 295(5):H2113-H2127.

68. Yan A, Avraham T, Zampell JC, Haviv YS, Weitman E, Mehrara BJ. Adipose-derived stem cells promote lymphangiogenesis in response to VEGF-C stimulation or TGF-beta1 inhibition. Future Oncol. 2011; 7(12):1457-1473. [PubMed: 22112321]

69. Hicklin DJ, Ellis LM. Role of the vascular endothelial growth factor pathway in tumor growth and angiogenesis. J Clin Oncol. 2005; 23(5):1011-1027. [PubMed: 15585754]

70. Chen JC, Chang YW, Hong CC, Yu YH, Su JL. The role of the VEGF-C/VEGFRs Axis in Tumor Progression and Therapy. Int J Mol Sci. 2012; 14(1):88-107. [PubMed: 23344023]

71. Kataru RP, Kim H, Jang C, et al. T lymphocytes negatively regulate lymph node lymphatic vessel formation. Immunity. 2011; 34(1):96-107. [PubMed: 21256057]

72. Zampell JC, Avraham T, Yoder N, et al. Lymphatic function is regulated by a coordinated expression of lymphangiogenic and antilymphangiogenic cytokines. Am J Physiol Cell Physiol. 2012; 302(2):C392-C404. [PubMed: 21940662]

73. Baluk P, McDonald DM. Markers for microscopic imaging of lymphangiogenesis and angiogenesis. Ann NY Acad Sci. 2008; 1131:1-12. [PubMed: 18519955]

74. Kriehuber E, Breiteneder-Geleff S, Groeger M, et al. Isolation and characterization of dermal lymphatic and blood endothelial cells reveal stable and functionally specialized cell lineages. $\mathrm{J}$ Exp Med. 2001; 194(6):797-808. [PubMed: 11560995]

75. Podgrabinska S, Braun P, Velasco P, Kloos B, Pepper MS, Skobe M. Molecular characterization of lymphatic endothelial cells. Proc Natl Acad Sci USA. 2002; 99(25):16069-16074. [PubMed: 12446836]

76. Hirakawa S, Hong YK, Harvey N, et al. Identification of vascular lineage-specific genes by transcriptional profiling of isolated blood vascular and lymphatic endothelial cells. Am J Pathol. 2003; 162(2):575-586. [PubMed: 12547715]

77. Makinen T, Norrmen C, Petrova TV. Molecular mechanisms of lymphatic vascular development. Cell Mol Life Sci. 2007; 64(15):1915-1929. [PubMed: 17458498] 
78. Hu X, Jiang Z, Liu N. A novel approach for harvesting lymphatic endothelial cells from human foreskin dermis. Lymphat Res Biol. 2006; 4(4):191-198. [PubMed: 17394402]

79. Nelson GM, Padera TP, Garkavtsev I, Shioda T, Jain RK. Differential gene expression of primary cultured lymphatic and blood vascular endothelial cells. Neoplasia. 2007; 9(12):1038-1045. [PubMed: 18084611]

80. Dixon JB, Raghunathan S, Swartz MA. A tissue engineered model of the intestinal lacteal for evaluating lipid transport by lymphatics. Biotechnol Bioeng. 2009; 103(6):1224-1235. [PubMed: 19396808]

81-. Ng CP, Helm CL, Swartz MA. Interstitial flow differentially stimulates blood and lymphatic endothelial cell morphogenesis in vitro. Microvasc Res. 2004; 68(3):258-264. Stresses the importance of dynamic fluid flow on shaping lymphatic endothelial cell organization in vitro. [PubMed: 15501245]

82. Boardman KC, Swartz MA. Interstitial flow as a guide for lymphangiogenesis. Circ Res. 2003; 92(7):801-808. [PubMed: 12623882]

83. Goldman J, Conley KA, Raehl A, et al. Regulation of lymphatic capillary regeneration by interstitial flow in skin. Am J Pathol Heart Circ Physiol. 2007; 292(5):H2176-H2183.

84. Dai T, Jiang Z, Li S, et al. Reconstruction of lymph vessel by lymphatic endothelial cells combined with polyglycolic acid scaffolds: a pilot study. J Biotechnol. 2010; 150(1):182-189. [PubMed: 20691226]

85. Cao R, Ji H, Feng N, et al. Collaborative interplay between FGF-2 and VEGF-C promotes lymphangiogenesis and metastasis. Proc Natl Acad Sci USA. 2012; 109(39):15894-15899. [PubMed: 22967508]

86. Hajrasouliha AR, Sadrai Z, Chauhan SK, Dana R. b-FGF induces corneal blood and lymphatic vessel growth in a spatially distinct pattern. Cornea. 2012; 31(7):804-809. [PubMed: 22467003]

87. Cao R, Bjorndahl MA, Gallego MI, et al. Hepatocyte growth factor is a lymphangiogenic factor with an indirect mechanism of action. Blood. 2006; 107(9):3531-3536. [PubMed: 16424394]

88. Yan A, Avraham T, Zampell JC, Aschen SZ, Mehrara BJ. Mechanisms of lymphatic regeneration after tissue transfer. PLoS One. 2011; 6(2):e17201. [PubMed: 21359148]

89. Wong AK, Schonmeyr B, Singh P, Carlson DL, Li S, Mehrara BJ. Histologic analysis of angiogenesis and lymphangiogenesis in acellular human dermis. Plast Recsonstr Surg. 2008; 121(4):1144-1152.

90. Harada K, Yamazaki T, Iwata C, et al. Identification of targets of PROX1 during in vitro vascular differentiation from embryonic stem cells: functional roles of HoxD8 in lymphangiogenesis. J Cell Sci. 2009; 122(Pt 21):3923-3930. [PubMed: 19825936]

91. Nonaka H, Watabe T, Saito S, Miyazono K, Miyajima A. Development of stabilin2 ${ }^{+}$endothelial cells from mouse embryonic stem cells by inhibition of TGFbeta/activin signaling. Biochem Biophys Res Commun. 2008; 375(2):256-260. [PubMed: 18706884]

92. Kono T, Kubo H, Shimazu C, et al. Differentiation of lymphatic endothelial cells from embryonic stem cells on OP9 stromal cells. Arterioscler Thromb Vasc Biol. 2006; 26(9):2070-2076. [PubMed: 16690875]

93. Hwang JH, Kim IG, Lee JY, et al. Therapeutic lymphangiogenesis using stem cell and VEGF-C hydrogel. Biomaterials. 2011; 32(19):4415-4423. [PubMed: 21421266]

94. Conrad C, Niess H, Huss R, et al. Multipotent mesenchymal stem cells acquire a lymphendothelial phenotype and enhance lymphatic regeneration in vivo. Circulation. 2009; 119(2):281-289. [PubMed: 19118255]

95. Giese C, Demmler CD, Ammer R, et al. A human lymph node in vitro - challenges and progress. Artif Organs. 2006; 30(10):803-808. [PubMed: 17026580]

96-. Suematsu S, Watanabe T. Generation of a synthetic lymphoid tissue-like organoid in mice. Nat Biotechnol. 2004; 22(12):1539-1545. Describes the feasibility of constructing artificial lymphoid organs using stromal and antigen-presenting cells embedded within a collagen matrix. [PubMed: 15568019]

97. Okamoto N, Chihara R, Shimizu C, Nishimoto S, Watanabe T. Artificial lymph nodes induce potent secondary immune responses in naive and immunodeficient mice. J Clin Invest. 2007; 117(4):997-1007. [PubMed: 17364025] 
98. Matsumoto M, Fu YX, Molina H, Chaplin DD. Lymphotoxin-alpha-deficient and TNF receptor-Ideficient mice define developmental and functional characteristics of germinal centers. Immunol Rev. 1997; 156:137-144. [PubMed: 9176705]

99. Zhang WJ, Liu W, Cui L, Cao Y. Tissue engineering of blood vessel. J Cell Mol Med. 2007; 11(5): 945-957. [PubMed: 17979876] 


\section{Executive summary}

\section{Lymphatic vascular system}

- The lymphatic vascular system is a unidirectional vascular network that is responsible for the maintenance of extracellular fluid homeostasis, lipid transport, and immune cell trafficking and immune response.

- The lymphatic endothelial cell (LEC) and the lymph node are the two key components to the lymphovascular network.

\section{Role of growth factors in lymphangiogenesis}

- A number of trophic factors have been identified for LECs.

- VEGF-C and its respective receptor VEGFR3 have been found to be the most potent and conserved molecules governing lymphangiogenesis.

- FGF and HGF also function as potent prolymphangiogenic growth factors, where TGF- $\beta$ and IFN- $\gamma$ act as antilymphangiogenic growth factors.

\section{Cellular models for studying lymphatics}

- Various models have highlighted the importance of interstitial flow in the regulation of lymphangiogenesis.

- LECs can be organized by 3D structures or scaffolds to facilitate tissue engineering of lymphatic vascular networks.

- Lymphatic vessels can spontaneously reconnect with existing lymphatic networks after tissue transfer.

- Progenitor cells, such as mesenchymal stem cells, can be utilized to enhance lymphatic regeneration and restore lymphatic fluid flow in the setting of lymphatic injury.

\section{Artificial organoids}

- Artificial lymphatic conduits have been designed within bioreactor systems comprised of agarose, polyamide fiber scaffolds, dendritic cells and mononuclear cells to tissue engineer functional lymphoid-like structures.

- Artificial constructs with transduced cells expressing lymphotoxin-a have resulted in complex formation of functional lymphoid-like structures as characterized by their cellular organization, chemoattraction of circulating lymphocytes and the presence of high endothelial venules. 


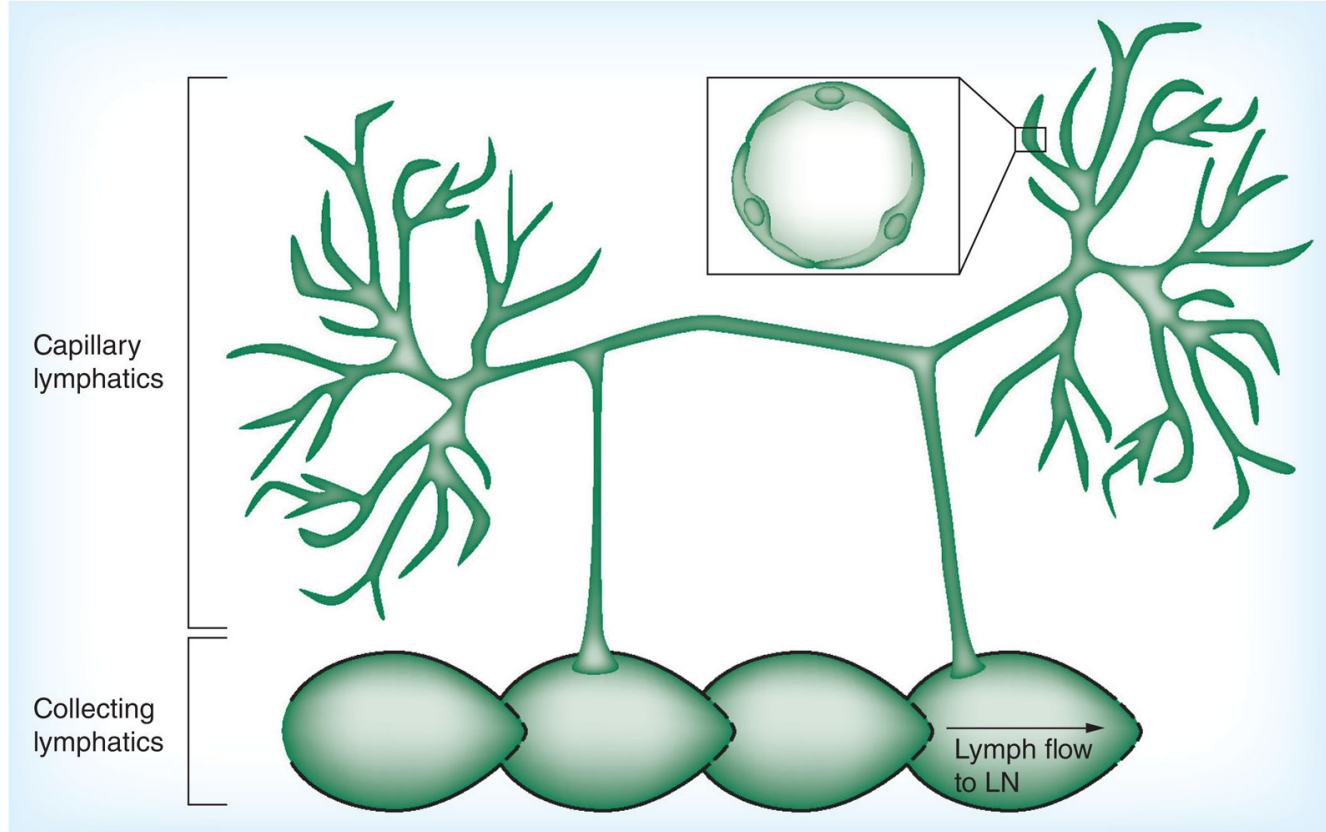

Figure 1. Lymphatic capillary and collecting system LN: Lymph node. 


\section{Table 1}

Cellular markers and characteristics of lymphatic and blood endothelial cells.

\begin{tabular}{|llll|}
\hline Characteristic & Capillary LECs & Collecting LECs & BECs \\
\hline Markers & LYVE-1, PROX, VEGFR3 & LYVE-1, PROX, VEGFR3 & $\begin{array}{l}\text { CD31, CD34, von Willebrand } \\
\text { factor }\end{array}$ \\
\hline Basement membrane & $\begin{array}{l}\text { Patchy, composed of laminin and } \\
\text { collagen type IV }\end{array}$ & $\begin{array}{l}\text { Multilayered, composed of laminin and } \\
\text { collagen type IV }\end{array}$ & $\begin{array}{l}\text { Multilayered, composed of } \\
\text { laminin and collagen type IV }\end{array}$ \\
\hline Subunits & None & Lymphangions & None \\
\hline Valves & None & Present & Present in veins \\
\hline Smooth muscle wall & None & Present & Present \\
\hline
\end{tabular}

BEC: Blood endothelial cell; LEC: Lymphatic endothelial cell. 